\title{
Protein levels and gene expressions of the epidermal growth factor receptors, HER1, HER2, HER3 and HER4 in benign and malignant ovarian tumors
}

\author{
KARINA DAHL STEFFENSEN ${ }^{1,4,5}$, MARIANNE WALDSTR $\varnothing M^{2}$, RIKKE FREDSLUND ANDERSEN ${ }^{3}$, \\ DORTE AALUND OLSEN ${ }^{3}$, ULLA JEPPESEN $^{4}$, HANS JØRGEN KNUDSEN $^{4}$, \\ IVAN BRANDSLUND ${ }^{3,5}$ and ANDERS JAKOBSEN ${ }^{1,5}$ \\ Departments of ${ }^{1}$ Oncology, ${ }^{2}$ Pathology and ${ }^{3}$ Clinical Biochemistry, Vejle Hospital, Kabbeltoft 25, DK-7100 Vejle; \\ ${ }^{4}$ Department of Gynecology and Obstetrics, Horsens Hospital, Sundvej 30, DK-8700 Horsens; \\ ${ }^{5}$ Institute for Regional Health Sciences, University of Southern Denmark, Odense, Denmark
}

Received February 12, 2008; Accepted March 31, 2008

\begin{abstract}
The epidermal growth factor receptors, HER1, HER2, HER3 and HER4 play a key role in the growth of malignant tumors. The receptors of the EGF receptor family are not cancer-specific proteins since these receptors are expressed to some extent in both normal and benign tissue, but this is not elucidated in detail in ovarian tissue. High tumor-to-normal-tissue concentration ratios would be favorable for molecular targeted anti-cancer treatment. The primary aim of the study was to analyze the potential differential protein content and gene expression of the four receptors in benign and malignant ovarian tumors. Tissue from 207 patients (101 malignant, 19 borderline, 64 benign ovarian tumors and 23 normal ovaries) were analyzed by quantitative ELISA for HER1-HER4 protein concentrations and by real-time PCR for HER1-HER4 gene expression. HER2 was also analyzed by immunohistochemistry. The HER2-4 receptor protein content and the median gene expression level was significantly higher in ovarian cancer patients compared to patients with benign ovarian tumors and normal ovaries $(\mathrm{p}<0.0000001)$. The protein content of the HER1 receptor was significantly lower in ovarian cancer compared to borderline tumors $(\mathrm{p}=0.012)$, benign ovarian tumors $(\mathrm{p}=0.049)$ and to normal ovaries $(\mathrm{p}=0.000069)$. A sound correlation between the protein levels and gene expressions was documented. In conclusion, decreased concentration of HER1 protein and increased HER2, HER3 and HER4 protein concentration were observed, as
\end{abstract}

Correspondence to: Dr Karina Dahl Steffensen, Department of Oncology, Vejle Hospital, Kabbeltoft 25, DK-7100 Vejle, Denmark E-mail: karina.dahl.steffensen@vgs.regionsyddanmark.dk

Key words: ovarian cancer, EGFR, HER1, HER2, HER3, HER4, correlation, protein concentration, gene expression, immunohistochemistry also elevated HER2-HER4 gene expression levels in ovarian cancer patients with barely any overlap of the HER3 and HER4 expression in malignant ovarian tumors compared to benign ovarian tissues.

\section{Introduction}

The EGF receptors are cell surface receptors that belong to the family of epidermal growth factor receptors, which play a crucial role for the growth of both normal tissue and malignant tumors. Four different membrane-bound receptors are known: the epidermal growth factor receptor, HER1 (EGFR/ErbB-1), HER2 (c-erbB2/neu), HER3 (c-erbB3) and HER4 (c-erbB4).

Many different ligands, including epidermal growth factor (EGF) and other ligands (TGF- $\alpha$, amphiregulin and heregulins) bind to the extracellular ligand-binding domain and cause two inactive receptors monomers to pair and form an active homodimer or heterodimer (when two different members of the EGFR subfamily dimerize). This dimerization activates the intracellular tyrosine kinase and phosphorylates the intracellular domains which again induces a cascade of complex signaling pathways, such as the phosphatidylinositol 3-kinase (PI3K)-AKT pathway and the MAPK pathway, that regulates cell proliferation, differentiation, migration, adhesion and apoptosis (1).

No ligands for the HER2 receptor has yet been identified and the HER3 receptor does not seem to have self-contained intrinsic tyrosine kinase activity, thus the action of HER2 and HER3 depends upon heterodimeric partnership with the other EGF receptors. Overexpression of HER1 and HER2 receptors has been associated with accelerated tumor progression and resistance to chemotherapy for multiple types of malignancies $(2,3)$.

Despite the numerous studies on the expression and clinical significance of HER1 (4-6) and HER2 (3,7-9), the role of these receptors are still controversial in ovarian cancer. Furthermore, only few studies have described the tissue expression of the HER3 and HER4 receptor protein in ovarian 
cancer. The HER3 receptor is present in the majority of malignant ovarian tumors (10-13) and one study (14) has also reported that high HER3 expression is a poor prognostic factor in ovarian cancer.

Conflicting results have been reported on HER4 expression. One study (15) found HER4 immunohistochemical expression in $89-93 \%$ in 53 patients with ovarian cancer. Another study (13) found no HER4 expression in 17 patients with ovarian cancer examined by Western blotting and a third study (16) found HER4 expressed in one out of ten ovarian cancer patients examined by immunohistochemistry.

There is, however, no comprehensive analysis of the expression of all four receptors in normal ovaries, benign or borderline ovarian tumors since most studies have investigated the expression in malignant tissue and only by using one detection method.

To our knowledge no other study has investigated either the gene expression of HER3 and HER4, or the quantitative protein concentrations in benign or malignant ovarian tissues.

HER 1 and HER2 have been described in more detail in ovarian cancer but most studies used immunohistochemical detection of the receptors and the majority of studies were performed on malignant ovarian tumors only.

The receptors of the EGF receptor family are not cancerspecific proteins, which are absent in normal cells. Current data indicate that some of these receptors are expressed to some extent in both normal and benign tissue, but there are no detailed comparisons. High tumor-to-normal-tissue concentration ratios would be favorable for tumor therapy, if any of these receptors are to be used as targets for molecular targeted anti-cancer treatment.

The primary aim of the present study was to measure the quantitative protein concentrations of the four receptors as well as their gene expression levels with the purpose of elucidating the potential different expression in normal, benign, borderline and malignant ovarian tissue.

The second aim of the present work was to examine the correlation between gene expression and protein expression for HER1-HER4 as well as the potential association between the expressions of the receptors.

\section{Patients and methods}

Patient data. The study population consisted of 207 unselected patients undergoing surgery for a previously untreated pelvic mass during the period from March 2005 to May 2007. The samples were, after informed consent, collected consecutively. Within 5 min after tumor removal by surgery a tissue sample was obtained. Half of the sample was divided into smaller samples of which some were snap-frozen in liquid nitrogen and stored at $-80^{\circ} \mathrm{C}$ until investigation while other small samples were fixed immediate in RNA stabilization reagent (RNAlater, Qiagen GmbH, Hilden, Germany) and stored at $-20^{\circ} \mathrm{C}$ as recommended by the manufacturer. The other half of the sample was fixed in formalin and paraffin-embedded for routine histological examination to ensure that the frozen samples and the RNAlater fixed tissue contained representative tissue. All pathological investigations were performed by a dedicated gynecological pathologist.
The tumors were diagnosed according to WHO 2003 criteria and graded using the Silverberg criteria. Twenty-three patients undergoing oophorectomy and/or hysterectomy for benign non-ovarian diseases served as controls. Histopathologic examination confirmed that their ovaries were normal. The Danish Biomedical Research Ethics Committee and the Danish Data Protection Agency approved the study.

\section{HERI-HER4 protein concentrations}

Extraction of proteins. Tissue samples $\sim 60 \mathrm{mg}$ were homogenized in $600 \mu 1$ lysate buffer $(20 \mathrm{mM}$ Tris- $\mathrm{HCl}$, $150 \mathrm{mM} \mathrm{NaCl}, 1 \mathrm{mM}$ EDTA, pH 7.4, $10 \%$ glycerol, $1 \%$ Triton X-100 and protease inhibitors) using a modified program for Maxwell $^{\mathrm{TM}} 16$ Instrument (Promega, Madison, WI, USA). After homogenization, the lysate was left to stand at $4^{\circ} \mathrm{C}$ for $30 \mathrm{~min}$ followed by centrifugation at $16000 \mathrm{~g}$ for $15 \mathrm{~min}$ at $4^{\circ} \mathrm{C}$. The supernatants were recovered and the protein concentration of each sample was determined using the BCA protein assay (Pierce, Rockford, IL, USA). All results for HER1-HER4 were normalized to the protein concentration.

HER 1. A commercially available enzyme-linked immunosorbent assay (Siemens/Oncogene Science, Cambridge, MA, USA) was used to quantify EGFR in ovarian tissue. Tissue extracts were diluted 50 times in sample diluent and added along with standards and controls (Oncogene Science, USA) to a 96-well microtiter plate coated with a mouse monoclonal anti-(EGFR) antibody. The plate was incubated for $1.5 \mathrm{~h}$ at $37^{\circ} \mathrm{C}$. After this incubation step, plates were washed and incubated with an alkaline phosphatase-labeled mouse monoclonal anti-(EGFR) antibody for $0.5 \mathrm{~h}$ at room temperature. After washing enzymatic reactions were carried out at room temperature by adding BluePhos substrate and the reaction was stopped after $1 \mathrm{~h}$ by the addition of stop solution. Color development was measured at $650 \mathrm{~nm}$ by using an automated plate reader (Molecular Devices, Sunnyvale, CA, USA) and the EGFR concentration of the unknown samples were estimated from the standard curve. All samples were analyzed in duplicate and the average of the two was recorded.

HER2. HER 2 in ovarian tissue was quantified by the HER-2/ neu assay for the ADVIA Centaur system (Siemens, Tarrytown, NY, USA) as described (17). The ADVIA Centaur HER-2/neu assay is an automated sandwich immunoassay in two steps using direct chemiluminescent technology. The assay utilizes two monoclonal antibodies (TA-1 and NB-3), one conjugated to fluorescein and the other to acridinium ester, which are specific for two different epitopes of the extracellular domain of HER2. The sample is co-incubated with TA-1 and NB-3 for $5.5 \mathrm{~min}$. After incubation, solid phase, which is composed of purified monoclonal anti-fluorescein antibody covalently coupled to paramagnetic particles, is added and the mixture is incubated for a further $2.75 \mathrm{~min}$. After this final incubation, the immunocomplex formed is washed with water, the reaction is initiated and the chemiluminescence measured is directly proportional to the quantity of HER2 antigen in the sample.

HER3. A DuoSet ELISA Development kit (R\&D Systems, Minneapolis, MN, USA) was used to quantify HER3 in ovarian 


\begin{tabular}{llll} 
& Forward primer & Reverse primer & Probe \\
\hline HER 1 & acc tat gtg cag agg aat tat gat ctt & gag ggc at gag gac ata acc a & 6FAM-tta aag acc atc cag gag gt-MGB \\
HER2 & ggt aca gtg agg acc cca cag tac & ggc tgg ttc aca tat tca ggc t & 6FAM-ccc cct gac ctc cag-MGB \\
HER3 & cta gcc aat gag ttc acc agg at & agg ccc act ctc tct ctt tat gac & 6FAM-aga ccc acc acg gta t-MGB \\
HER4 & ctc tcc ttc ctg cgg tct gt & aac gaa act gat taa gag cca cta aca & 6FAM-cga gaa gtc aca ggc t-MGB
\end{tabular}

Figure 1. Primer and probes used for HER1-HER4 gene expression analysis.

tissue. The plate was coated with a mouse anti-human HER-3 antibody using $4.0 \mu \mathrm{g} / \mathrm{ml}$ and left to stand $\mathrm{ON}$ at room temperature. The plate was washed in PBS containing $0.05 \%$ Tween-20 $0^{\circledR}$, blocked for $1 \mathrm{~h}$ using PBS with $1 \%$ BSA and washed again. Tissue extracts were diluted 50 times in PBS with $1 \%$ BSA. Diluted tissue samples along with standards and controls were dispensed in duplicates to a 96-well plate and incubated for $2 \mathrm{~h}$ at room temperature. The plate was washed and incubated for $2 \mathrm{~h}$ at room temperature in the presence of a biotinylated mouse anti-human HER-3 antibody using $0.5 \mu \mathrm{g} / \mathrm{ml}$. After washing HRP-conjugated streptavidin was added and the plate was left to stand for $0.5 \mathrm{~h}$ at room temperature. The plate was washed and developed using a 1:1 mixture of tetramethylbenzidine and $\mathrm{H}_{2} \mathrm{O}_{2}$ and the reaction was stopped after 0.5-h incubation using $2 \mathrm{~N} \mathrm{H}_{2} \mathrm{SO}_{4}$. Bound HER-3 was detected by measuring the absorbance at $450 \mathrm{~nm}$ by using an automated plate reader (Molecular Devices) and the HER-3 concentration of the samples was determined from the standard curve.

HER4. A commercially available DuoSet ELISA Development kit (R\&D Systems) was used to quantify HER4 in ovarian tissue. The plate was coated with a mouse anti-human HER4 antibody using $4.0 \mu \mathrm{g} / \mathrm{ml}$. The steps were the same as described for HER3 except for the secondary antibody used, which were a biotinylated mouse anti-human HER4 antibody used at a concentration of $0.25 \mu \mathrm{g} / \mathrm{ml}$.

HER2 immunohistochemistry. Immunostaining was performed on one $4-\mu \mathrm{m}$ slide from each patient using the HercepTest ${ }^{\mathrm{TM}}$ (DakoCytomation, Glostrup, Denmark) as previously described (18). Positive controls (breast cancer tissue with a 3+ HER2 reaction) were examined together with every tumor slide. The interpretation of HER2 expression was done by two of the authors (K. Dahl Steffensen and M. Waldstrøm). At the time of interpretation none of the authors had any knowledge of the clinical data.

\section{HER1-HER4 gene expression}

$R N A$ purification. For purification of RNA from the tissue fixed in RNAlater the Maxwell 16 Total Purification Kit (Promega) was used according to the manufacturer's instructions. In brief, the tissue was cut into small pieces and $400 \mu 1$ of RNA lysis buffer was added followed by homogenization using a FastPrep FP120 (BIO 101, Qbiogene, Carlsbad, CA) and cooling on ice. $670 \mu 1$ RNA Dilution Buffer was then added to precipitate sample debris followed by $75 \mu \mathrm{l}$ Clearing Agent to remove genomic DNA. The sample was subsequently heated to $70^{\circ} \mathrm{C}$ for $3 \mathrm{~min}$, mixed, incubated for $5 \mathrm{~min}$ at room temperature, transferred to the Clearing Column and cleared by centri- fugation. The lysate was transferred to well no. 1 of the Maxwell RNA Cartridge.

RNA concentration was measured in 96-well format by Quant-iT RiboGreen ${ }^{\circledR}$ RNA Quantitation Kit (R-11490, Invitrogen, Molecular Probes, CA, USA) according to the manufacturer's instructions. Fluorescence was measured in triplicate (FL600 Microplate Fluorescence Reader, BioTek Instruments, Vermont, USA). From the standard curve the fluorescent signal was converted to a concentration of RNA (ng/ $/ 1)$.

cDNA synthesis and quantification of HER1-HER4 mRNA expression. cDNA synthesis was performed in triplicate using Primer 'random' (Roche Applied Science, Mannheim, Germany) according to the manufacturer's instructions (150 ng RNA to a final volume of $15 \mu \mathrm{l}$ c-DNA reaction $(10 \mathrm{ng} / \mu \mathrm{l})$, Buffer II, $\mathrm{MgCl}_{2}$, MuLV Reverse Transcriptase and RNase Inhibitor (Applied Biosystems, Foster City, CA, USA). Results were corrected before analysis if lower amounts of RNA were added (10 samples with 95-149 ng RNA in $15 \mu 1$ total volume of c-DNA reaction). Samples with $<95 \mathrm{ng}$ RNA in $15 \mu 1$ total volume of c-DNA reaction were not included in the analyses.

Expression of HER1-4 mRNA was measured using real-time PCR on the ABI PRISM HT 7900 Sequence Detection System, TaqMan (Applied Biosystems, Foster City, CA, USA). The PCR reaction mixture contained $2 \mu 1$ of cDNA, $12.5 \mu 1$ TaqMan Gene Expression Master Mix, forward and reverse primer (final concentration of each primer: HER1 and HER2, $600 \mathrm{nM}$; HER3 and HER4, $300 \mathrm{nM}$ ) and $250 \mathrm{nM}$ TaqMan probe in a final volume of $25 \mu 1$. The cycling conditions for PCR amplification were performed according to the manufacturer's instructions. Primers were designed using the Primer Express 3.0 program and purchased from Applied Biosystems (Cheshire, UK). Probes were 6-FAM labeled MGB probes (Fig. 1).

Quantification of HER1 and HER2 was performed by using a standard curve of Stratagene QPCR Human Reference Total RNA (Stratagene, La Jolla, CA, USA). Quantification of HER3 and HER4 was performed by using a standard curve obtained from RNA from the MCF7 cell line. The MCF7 cell line was a kind gift from Dr Boe Sandahl Sørensen, Aarhus University Hospital, Aarhus, Denmark. For each PCR reaction, negative [samples without cDNA $\left(\mathrm{H}_{2} \mathrm{O}\right)$ ] and positive (samples of known concentration) controls were performed.

Statistical analyses. Statistical analyses were performed with the NCSS software (version 2001, Kaysville, UT, www.ncss. com). Protein concentrations and gene expression levels were 
Table I. Patient characteristics.

\begin{tabular}{|c|c|c|}
\hline Characteristics & $\mathrm{N}$ & $\%$ \\
\hline \multicolumn{3}{|l|}{ Age } \\
\hline$\leq 40$ & 16 & 7.7 \\
\hline $40-65$ & 111 & 53.6 \\
\hline$>65$ & 80 & 38.7 \\
\hline \multicolumn{3}{|l|}{ Histopathologic diagnosis } \\
\hline Malignant ovarian tumor & 101 & 45.5 \\
\hline Serous & 71 & $(70.3)$ \\
\hline Mucinous & 3 & $(3.0)$ \\
\hline Endometrioid & 9 & $(8.9)$ \\
\hline Clear cell & 4 & $(4.0)$ \\
\hline Undifferentiated & 1 & $(1.0)$ \\
\hline Mixed epithelial & 1 & $(1.0)$ \\
\hline Serous (tubal) & 3 & $(3.0)$ \\
\hline Serous (peritoneal) & 5 & $(5.0)$ \\
\hline Carcinosarcoma & 3 & $(3.0)$ \\
\hline Malignant Brenner & 1 & $(1.0)$ \\
\hline Borderline ovarian tumor & 19 & 8.6 \\
\hline Serous & 10 & $(52.6)$ \\
\hline Mucinous & 8 & $(42.1)$ \\
\hline Endometrioid & 1 & $(5.3)$ \\
\hline Benign ovarian tumor & 64 & 28.9 \\
\hline Serous cystadenoma & 9 & $(14.1)$ \\
\hline Mucinous cystadenoma & 15 & $(23.4)$ \\
\hline Simple cyst & 5 & $(7.8)$ \\
\hline Dermoid cyst & 7 & $(10.9)$ \\
\hline Endometriosis cyst & 12 & $(18.8)$ \\
\hline Ovarian fibroma & 6 & $(9.4)$ \\
\hline Serous cystadenofibroma & 7 & $(10.9)$ \\
\hline Other & 3 & $(4.7)$ \\
\hline Normal ovaries (control group) & 23 & 10.4 \\
\hline \multicolumn{3}{|l|}{ FIGO stage (ovarian cancer group) } \\
\hline I & 18 & 18.0 \\
\hline II & 10 & 10.0 \\
\hline III & 57 & 57.0 \\
\hline IV & 15 & 15.0 \\
\hline (Unknown:1) & & \\
\hline \multicolumn{3}{|l|}{ Histological tumor grade } \\
\hline Well differentiated (grade 1) & 14 & 14.7 \\
\hline Moderately differentiated (grade 2) & 31 & 32.6 \\
\hline $\begin{array}{l}\text { Poorly differentiated (grade 3) } \\
\text { (NA/Unknown: 6) }\end{array}$ & 50 & 52.6 \\
\hline
\end{tabular}

not normally distributed and the median, the $95 \%$ confidence intervals for the median and the range were therefore chosen for data description.
Differences between the patient groups were tested with the non-parametric Mann-Whitney U test. The correlation between protein concentrations and gene expression levels as well as the association between the receptors were calculated by linear regression by fitting a linear equation to the observed data. The strength of the linear association between two variables is reported by the correlation coefficient and by $\mathrm{p}$-values and $\mathrm{r}^{2}$ (the square of the correlation coefficient which represents the fraction of the variation in one variable that may be explained by the other variable). The different statistics applied to the data are described in the text and figures.

\section{Results}

Patient and tumor characteristics are summarized in Table I. The median age for all the included patients was 60.0 years (range 20-88 years), $45.5 \%$ of the included patients had an ovarian cancer and the majority of these patients were diagnosed at an advanced stage. As shown in Table I 8.6\% of the patients had a borderline tumor, $28.9 \%$ a benign ovarian tumor and $10.4 \%$ had normal ovaries. The median age for the ovarian cancer patients, borderline ovarian tumors, benign ovarian tumors and patients with normal ovaries were 66.5, $58.7,57.6$ and 50.2 years respectively.

Protein concentrations of HER1-HER4. From the 207 included patients, 200 samples were obtained for quantitative protein determination. Seven samples were either missing or excluded because the paraffin-embedded formalin fixed control revealed there was not sufficient tumor tissue in the biopsy. From the 200 fresh frozen biopsies, HER1 and HER4 results were available for all the samples. HER2 results were available from 193 patients ( 7 samples were undetermined) and HER3 from 195 patients (1 sample were missing and 4 samples were undeterminable because of a protein concentration below the standard curve; these samples with low concentrations were one patient with ovarian cancer and three patients with benign tumors).

Median HER1-HER4 protein concentrations are shown in Table IIA for the four different patient groups. The median protein concentrations, for all four receptors, in ovarian cancer patients were significantly different from both patients with benign tumors and patients with normal ovaries. Except for HER1 there was no significant difference between invasive ovarian cancer and borderline ovarian tumors. It is noteable that HER1 protein concentration was lower in the ovarian cancer patients compared to all other diagnostic groups. This is in contrast to HER2-4 where the protein concentrations were higher in the tumor tissue compared to normal and benign tumor tissue.

There was no significant correlation between HER1-3 protein concentrations and age (linear regression analysis, data not shown), but higher HER4 protein concentrations were correlated with increasing age. The cancer patients were significantly older than the other patient groups and age could therefore be a potential confounder for the differences found in HER4 protein concentrations. Multivariate logistic regression models (data not shown) found that the association between HER4 protein concentration and diagnosis were not 
Table II.

A, HER 1-4 protein levels.

\begin{tabular}{|c|c|c|c|c|}
\hline A & $\begin{array}{c}\text { HER1 } \\
\text { ng/mg protein }\end{array}$ & $\begin{array}{l}\text { ein concentratic } \\
\text { HER } 2 \\
\text { ng/mg protein }\end{array}$ & $\begin{array}{c}\text { HER3 } \\
\text { ng/mg protein }\end{array}$ & $\begin{array}{c}\text { HER4 } \\
\mathrm{ng} / \mathrm{mg} \text { protein }\end{array}$ \\
\hline Ovarian cancer & 6.95 & 36.8 & 2.4 & 0.89 \\
\hline [95\% CI median] & {$[5.2-8.1]$} & {$[30-46]$} & {$[1.9-3.1]$} & {$[0.68-1.2]$} \\
\hline (Range) & $(0.3-65.4)$ & $(0.2-855)$ & $(0.02-15.7)$ & $(0.06-11.8)$ \\
\hline Borderline tumors & 10.3 & 27.8 & 3.4 & 0.67 \\
\hline [95\% CI median] & {$[6.3-20.7]$} & [14-40] & {$[1.5-13.8]$} & {$[0.37-1.2]$} \\
\hline (Range) & $(4.3-116.2)$ & $(13-58)$ & $(0.5-70.1)$ & $(0.13-2.9)$ \\
\hline p-value & 0.012 & 0.14 & 0.09 & 0.34 \\
\hline Benign tumors & 8.7 & 14.8 & 0.52 & 0.27 \\
\hline [95\% CI median] & {$[6.9-10.1]$} & [13-16] & {$[0.38-0.73]$} & {$[0.20-0.35]$} \\
\hline (Range) & $(0.9-21.9)$ & $(0.2-62)$ & $(0.02-26.7)$ & $(0.05-1.6)$ \\
\hline p-value & 0.049 & $<0.0000001$ & $<0.0000001$ & $<0.0000001$ \\
\hline Normal ovaries & 12.37 & 10.9 & 0.45 & 0.39 \\
\hline [95\% CI median] & [10.4-15.3] & [9-13] & [0.32-0.53] & [0.26-0.49] \\
\hline (Range) & $(3.7-19.3)$ & $(7-17)$ & $(0.23-2.6)$ & $(0.13-0.91)$ \\
\hline p-value & 0.000069 & $<0.0000001$ & $<0.0000001$ & 0.00005 \\
\hline
\end{tabular}

B, HER1-4 gene expression levels.

\begin{tabular}{|c|c|c|c|c|}
\hline B & \multicolumn{3}{|c|}{ Gene expression } & HER4 qmean \\
\hline Ovarian cancer & 56.0 & 239.2 & 28.3 & 189.6 \\
\hline [95\% CI median] & [43-69] & [187-269] & [22-32] & [125-253] \\
\hline (Range) & $(3.4-229)$ & $(37.9-4862)$ & $(1.1-173)$ & $(0.15-2835)$ \\
\hline Borderline tumors & 38.4 & 156.5 & 16.9 & 28.2 \\
\hline [95\% CI median] & {$[15-62]$} & [92-217] & [10-38] & {$[0.1-71]$} \\
\hline (Range) & $(0.5-213)$ & $(11.7 .6-399)$ & $(3.6-82)$ & $(0.06-349)$ \\
\hline $\mathrm{p}$-value & 0.062 & 0.030 & 0.23 & 0.000071 \\
\hline Benign tumors & 54.9 & 72.6 & 2.3 & 0.98 \\
\hline [95\% CI median] & {$[41-76]$} & [55-94] & {$[0.5-4.8]$} & {$[0.6-3.5]$} \\
\hline (Range) & $(8.3-138)$ & $(4.6-202)$ & $(0.02-167)$ & $(0.07-189)$ \\
\hline p-value & 0.59 & $<0.0000001$ & $<0.0000001$ & $<0.0000001$ \\
\hline Normal ovaries & 57.8 & 41.7 & 0.11 & 0.99 \\
\hline [95\% CI median] & [33-92] & [31-71] & [0.07-0.39] & [0.4-1.5] \\
\hline (Range) & $(23-189)$ & $(18-126)$ & $(0.02-19)$ & $(0.18-56)$ \\
\hline p-value & 0.81 & $<0.0000001$ & $<0.0000001$ & $<0.0000001$ \\
\hline
\end{tabular}

Results are presented as median and [95\% CI median]. P-values refer to the difference between the reported median and the median for ovarian cancer patients (Mann-Whitney U test for differences in medians).

confounded by age when age and protein concentrations both were entered in the models on a continuous scale. After correction for age there was still a significant difference between the high HER4 protein concentration in patients 
A

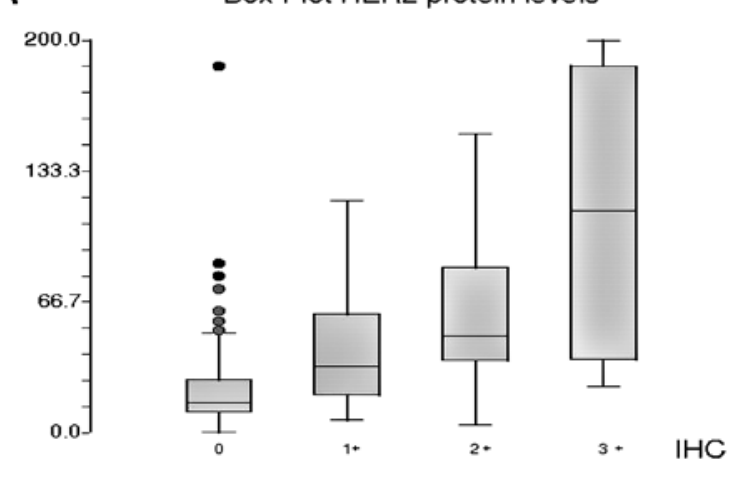

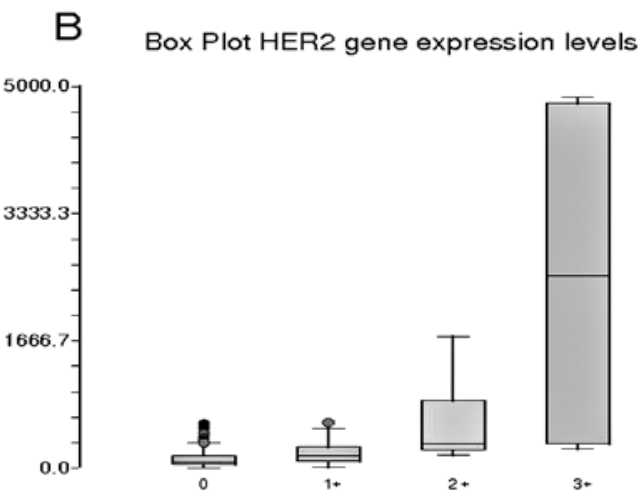

IHC

\begin{tabular}{ccccc}
\hline $\begin{array}{c}\text { HER2 } \\
\text { protein } \\
\text { expression }\end{array}$ & $\begin{array}{c}\text { Normal } \\
\text { ovaries }\end{array}$ & $\begin{array}{c}\text { Benign } \\
\text { ovarian } \\
\text { tumors }\end{array}$ & $\begin{array}{c}\text { Borderline } \\
\text { tumors }\end{array}$ & $\begin{array}{c}\text { Ovarian } \\
\text { cancer }\end{array}$ \\
IHC & $\mathbf{N}$ & $\mathbf{N}$ & $\mathbf{N}$ & $\mathbf{N}$ \\
\hline $\mathbf{0}$ & 23 & 51 & 11 & 52 \\
$\mathbf{1 +}$ & 0 & 12 & 8 & 33 \\
$\mathbf{2 +}$ & 0 & 0 & 0 & 9 \\
$\mathbf{3 +}$ & 0 & 0 & 0 & 5 \\
\hline
\end{tabular}

$\chi^{2}=44.9, p=0.000011$

Figure 2. Correlation between HER2 immunohistochemistry and A, HER2 protein concentrations (ng/mg protein); B, HER2 gene expression levels (qmean); C, HER2 immunohistochemical protein expression.

with ovarian cancer and the much lower concentration in patients with benign tumors $(\mathrm{p}<0.000001)$. The same applied to patients with normal ovaries $(\mathrm{p}=0.0016)$.

Except for higher HER1 protein concentrations in patients with ascites and higher HER4 protein concentrations in patient with grade 2 tumors no associations to classical clinicopathological parameters were found (data not shown). Although there were some differences between the different histological subtypes; mucinous adenocarcinomas showing significantly higher HER2 and HER3 concentrations and clear cell adenocarcinomas showing high HER2 concentrations, these subgroups were too small to make a comparison meaningful.

HER2 immunohistochemistry. Results from the immunohistochemical staining (IHC) were obtained from 204 patients. Data are presented in Fig. 2. In the ovarian cancer patients moderate (2+) immunohistochemical staining of HER2 protein were found in nine $(9.1 \%)$ out of 99 ovarian cancer specimens and intense staining (3+) in five (5.1\%) patients. Weak staining (1+) was found in $33.3 \%$ of the ovarian cancer patients. None of the other patient groups showed moderate or intense immunohistochemical staining. In the groups of borderline ovarian tumors, benign tumors and the control group of normal ovaries weak (1+) staining was observed in $42.1,19$ and $0 \%$ of the cases, respectively.

Increasing immunohistochemical staining was significantly correlated to increasing HER2 protein concentrations. For HER2 IHC $0,1+, 2+$ and $3+$ the median HER2 protein concentrations was 16.0, 34.3, 49.7 and $113.6 \mathrm{ng} / \mathrm{mg}$ protein, respectively (Fig. 2). Increasing immunohistochemical staining was also significantly correlated to increasing HER2 gene expression (Fig. 2).

The concordance between the two authors of the interpretation of the HER2 IHC expression was $82 \%$. Cohen's Kappa for interobserver reliability and reproducibility was 0.65 (Unweighted Kappa - Kappa with linear weighting was $0.72)$.

Gene expression HER1-HER4. Results for HER1-3 were obtainable from 187 out of the 207 patients included in this study: 20 samples could not be analyzed for gene expression; six samples were either missing or did not contain sufficient tumor tissue in the RNAlater preserved biopsy and 14 samples contained $<95$ ng RNA in $15 \mu 1$ total volume of c-DNA reaction and were therefore not included in the analyses. For HER4 gene expression analysis, an additional four samples (one ovarian cancer, two borderline tumors and one benign tumor) showed gene expression levels below the detection level obtained from the standard curve, so HER4 data from 183 patients were analyzed.

Median HER1-HER4 gene expression levels are shown in Table IIB for the different patient groups. The data presented in Table IIB clearly show that the expression of HER2-4 were significantly higher in the ovarian cancer patients compared to the patients with benign ovarian tumors and to patients with normal ovaries. The table also demonstrates a significant difference between the high HER2 and HER4 gene expression levels in ovarian cancer patients compared to the lower gene expression found in the borderline tumors. 

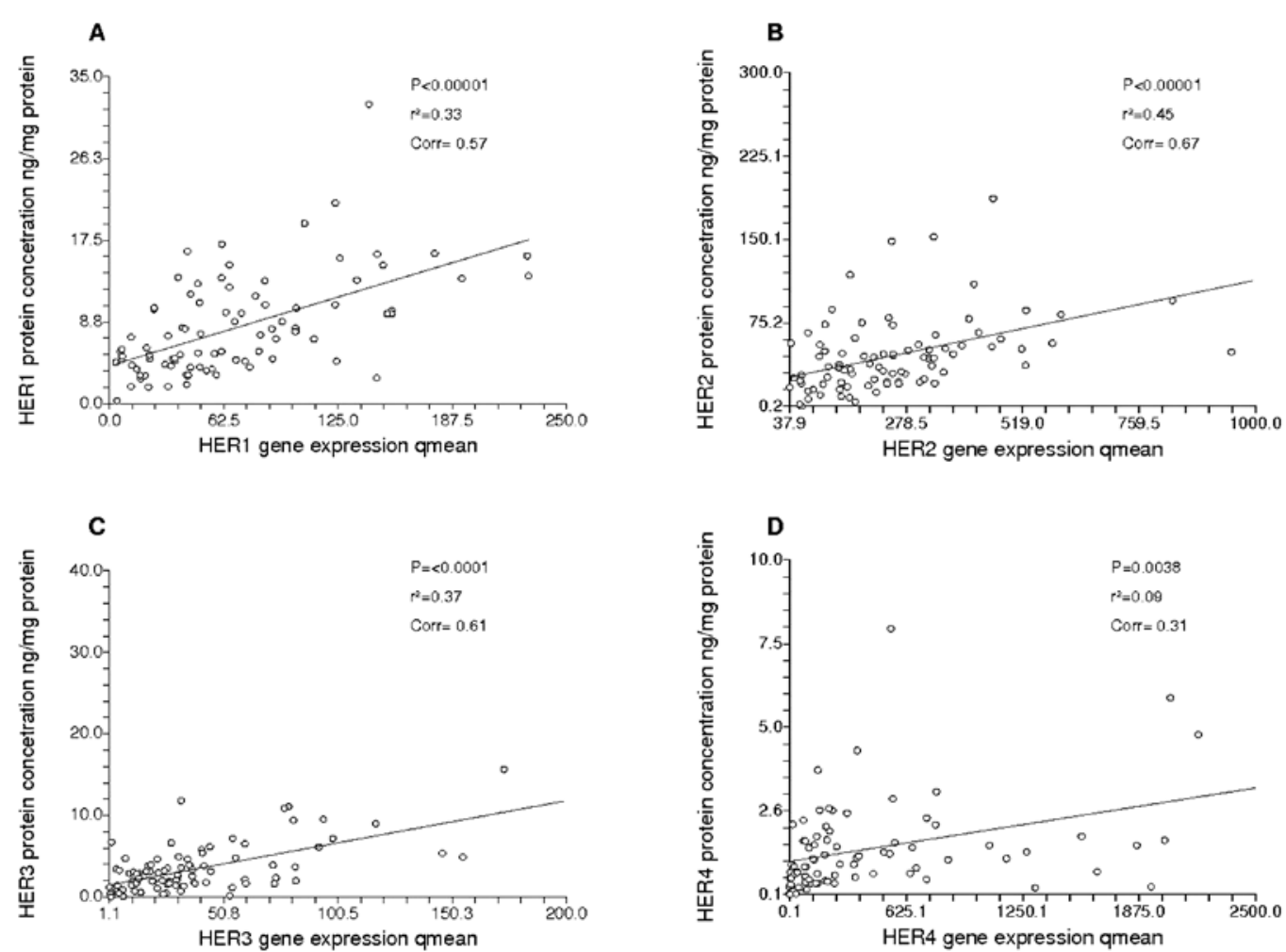

Figure 3. Correlation between protein concentrations and gene expression levels for HER1-HER4 in the ovarian cancer patients.

In contrast to our findings concerning protein concentrations there were no differences of the HER 1 gene expression levels between the different patient groups.

HER3 and HER4 gene expression increased significantly with increasing age. As described for the HER4 protein, age could therefore be a potential confounder in our findings. Again multivariate logistic regression calculations showed that this was not the case since the difference when comparing ovarian cancer patients to patients with benign tumor or to patients with normal ovaries were still highly significant after age adjustment (data not shown).

No statistical association with HER1-HER4 gene expression levels and clinicopathological characteristics except for higher HER4 median gene expression in grade 2 and 3 tumors were found (data not shown). Clear cell adenocarcinomas showed higher gene expression levels of HER2 and HER4 and mucinous adenocarcinomas showed higher expression of HER2, 3 and 4. As previously described, the histological subgroups were too small to make a comparison reasonable.

Correlation between protein concentration and gene expression. Linear regression analysis of the relationship between protein concentrations and gene expression were performed. These data are presented in Fig. 3. We identified a statistically significant positive correlation between the protein concentration and the gene expression level for all four receptors. Fig. 4 underlines that the low gene expression found for HER 3 and HER 4 translates into a low HER3 and HER4 protein concentration.

Association between HER1-HER4. High concentrations of HER2 protein were highly correlated with high concentrations of HER3 protein (correlation $0.41, \mathrm{p}<0.00001$ ) in the ovarian cancer patients. Also, a correlation between HER3 and HER4 protein levels were found (correlation $0.24, \mathrm{p}=0.03$ ). None of the other receptors were significantly associated. At the gene expression level the only correlation was seen between HER2 and HER4 (correlation 0.26, $\mathrm{p}=0.01$ ).

\section{Discussion}

Differences in protein expression as well as in gene expression levels between normal tissue and cancer tissue should be taken into account when exploring new targeted therapeutic regimens. A major challenge for all targeted therapies is to identify simple and effective therapeutic targets. Accurate measurement of the targets is also essential. Most studies on ovarian cancer and HER2 have evaluated the HER2 protein expression by immunohistochemistry and fluorescence in situ hybridization (FISH) with a high reported concordance between these two methods $(18,19)$. Nevertheless, immunohistochemistry is only semi-quantitative and for HER 1 there are severe difficulties in predicting response to anti-HER 1 therapies by HER1 immunohistochemical testing (20-23). To our knowledge, this is the first study that describes quantitative levels of all four receptors of the EGF receptor family in ovarian cancer as well as their gene expression levels. HER1 and HER2 are by far the two most studied receptors. In contrast, the literature on HER3 and HER4 in ovarian cancer is very limited.

Our present study indicate a major difference between the HER3 and HER4 gene expression in ovarian cancer compared to benign ovarian tumors and to normal ovarian tissue. HER3 and HER4 gene expression was very low in 
Box Plot HER3

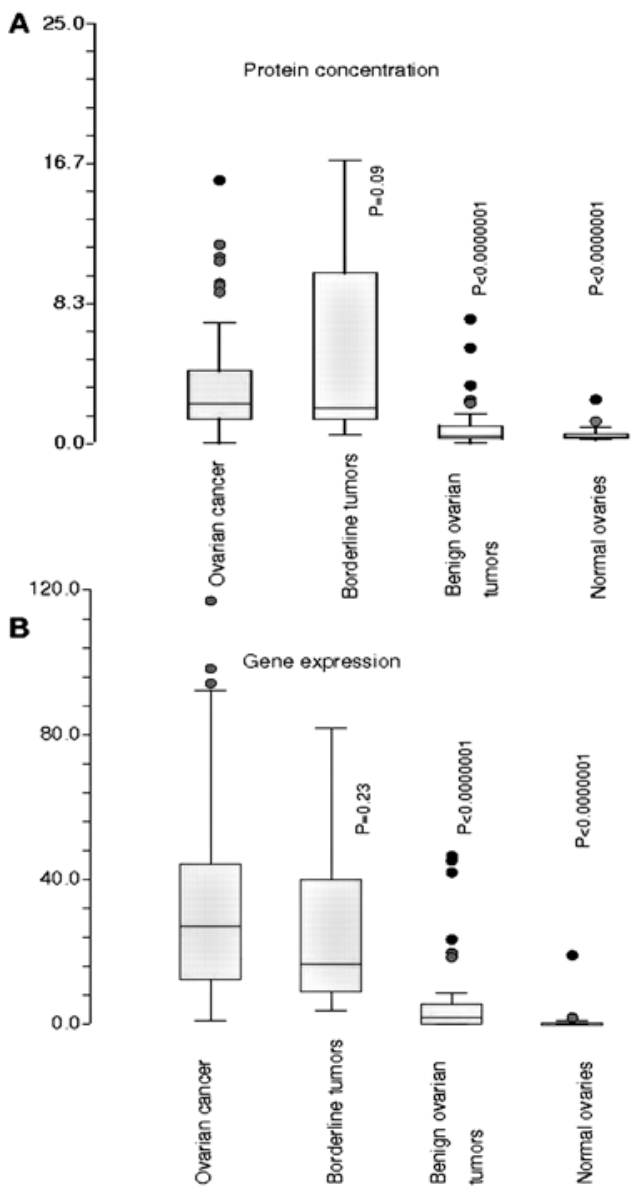

Box Plot HER4

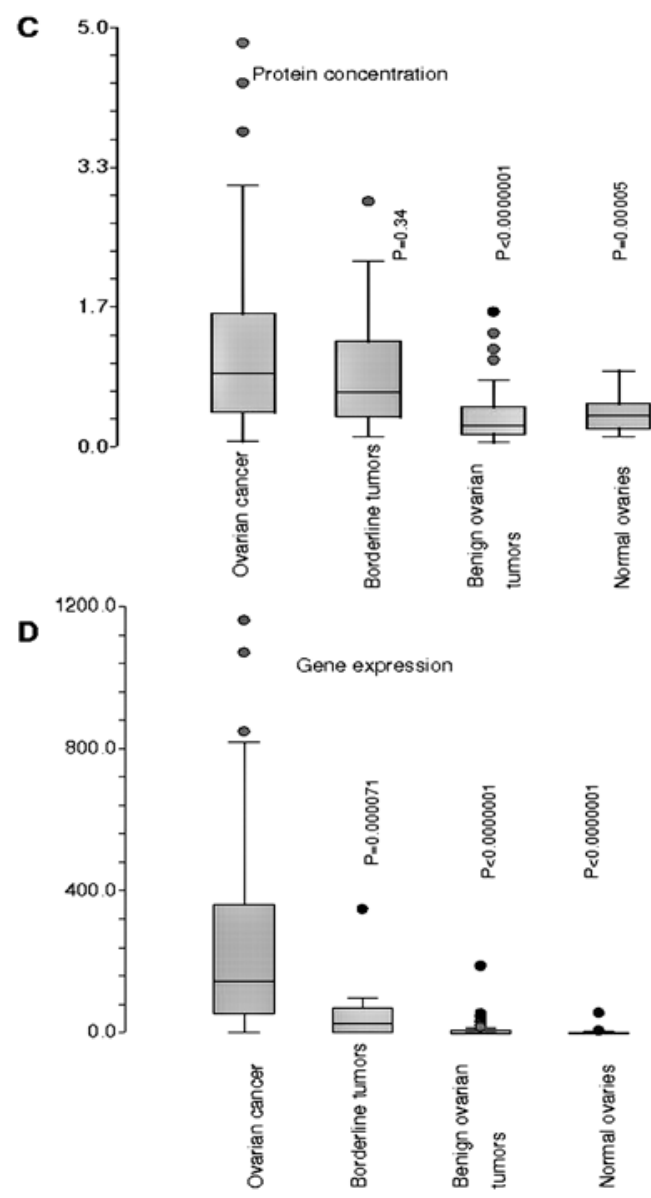

Figure 4. Box plots showing protein levels (A and C) and gene expression levels (B and D) for HER3 and HER4 in the different patient groups.

benign ovarian tumors and in normal ovarian tissue. This was underlined when translated into proteins where HER3 and HER4 protein concentrations showed to be significantly lower compared to the ovarian cancer group. Some genes are constitutive; others go from extremely low expression to high expression when 'turned on'. Our data indicate that the genes for HER3 and HER4 are almost completely turned off in normal ovaries and in benign ovarian tumors and at some point during carcinogenesis the expression of HER3 and HER4 get turned on and may exhibit a profound effect on cell pathophysiology. The HER2 analysis also revealed a highly significant difference between the patient groups, both at the gene expression level and at the protein level, although not as extensive as for HER3 and HER4.

Inconsistent results have been published with respect to the HER2 expression but the most recent studies seem to agree that only a minority of ovarian cancer overexpress HER2 $(9,18,24,25)$. This was also seen in our study where only a small group of the ovarian cancer patients showed 2+ or $3+$ overexpression by immunohistochemistry. Nevertheless, these studies almost exclusively measured HER 2 by immunohistochemistry or FISH and included only cancer patients. Our quantitative HER2 protein analyses indicate, on the contrary, that the majority of the ovarian cancer patients have significantly higher HER2 protein levels compared to benign ovarian tumors and to normal ovaries. Interestingly, a study by Menendez et al (26) investigated whether heregulin induced transactivation of HER2 affected breast cancer cell sensitivity to chemotherapy and whether trastuzumab (a monoclonal antibody targeted against the HER2 receptor) treatment in HER2 negative cells increased chemo-sensitivity when combined with chemotherapy. Trastuzumab did induce receptor-enhanced chemo-sensitivity in the absence of HER2 overexpression in this study, but the author also suggested that this probably occurred through the kinase activity of HER2/HER3 dimerization and when the HER3 activating ligand, heregulin was in excess. The HER2 expression was accessed through densitometric immunoblotting in the study and no data on quantitative HER2 concentrations were reported, although it would be interesting to investigate if the effect of trastuzumab were through inhibition of HER2/HER3 dimerization or due to increased HER2 levels not detected by the method used. In our study a correlation between HER2 and HER 3 protein concentrations were found and since the preferred partner for HER3 is known to be HER2 (27), this correlation holds promise for a biological significance in ovarian cancer. In breast cancer, HER2 overexpression has likewise shown to be highly correlated with HER3 overexpression (28). The signal produced from this particular partnership is supposed to be very potent and the most 
mitogenic dimerization (29) implying that the correlation of HER2 and HER3 found in our study could be a marker for the increased cell growth.

In the present study we found significantly decreased levels of HER1 protein in ovarian cancer patients compared to both benign and borderline ovarian tumors and also compared to patients with normal ovaries. Most published studies regarding HER1 have been performed on malignant tumor tissue and the vast majority of these studies measured HER1 expression using immunohistochemistry. HER1 overexpression has been reported in between $17-57 \%$ of the examined cases $(4,5,30-33)$. Two studies have investigated the HER1 expression in benign ovarian tissue. One study (34) reported HER1 expression in $15.4 \%$ of normal ovaries and $13.3 \%$ of benign ovarian tumors, but did not include any comparison to malignant tumor tissue. Another study (35) reported on HER1 immunohistochemical expression in $58.7 \%$ of included 63 ovarian cancer patients but also found HER 1 expression in $50 \%$ of the 6 patients included with benign tumors. As described above, the literature is very sparse in ovarian cancer and most studies are performed only in invasive tumors and do not include comparison to the expression levels in normal ovaries and benign ovarian tumors. Our study showed that HER1 protein levels in ovarian cancer are decreased compared to benign tumors and to normal ovaries and this has not been reported by others. Nevertheless, our observation in ovarian cancer agrees with previous work that reported on lower EGFR expression in breast cancer (36-38).

The decreased tissue levels of HER 1 could be due a system that is running very fast in a rapidly dividing tumor tissue with HER1 more or less constantly activated and hereby internalized, ubiquinated and degraded, so even though the HER1 levels seems to be low, the results we get from our analysis could be just a static picture of a dynamic process. This is suggested based on our data from the gene expression analysis showing no difference in the HER1 gene expression levels between the patient groups. This theory is also supported by data that have shown that the HER1 receptor upon ligand binding cluster over clathrin-coated regions of the cell membrane, which invaginates to form endocytotic vesicles. These vesicles mature to endosomes, while gradually decreasing their internal $\mathrm{pH}$ and accumulating hydrolytic enzymes that lead to receptor degradation. Interestingly, the other three HER receptors are endocytosis impaired and are more often recycled back to the surface (39).

Other explanations could be diminished levels of HER1 caused by formation of hetero- or homodimers of the EGFR family masking the epitopes recognized by the EGFR ELISA assay or autoantibodies complexing with the HER1 extracellular domain and masking epitopes recognized by the EGFR assay.

Understanding the expression of these receptors in cancer is more than an academic exercise. The epidermal growth factor receptor family represents an attractive target for cancer therapy.

Recently, many therapeutic agents targeting the epidermal growth factor receptor family have entered the clinic. Trials of both small-molecule tyrosine kinase inhibitors (TKIs) of EGFR and antibody-based inhibitors are underway in ovarian cancer and emerging data suggest that their activity in unselected women with advanced ovarian cancer is modest $(40,41)$. Finally, by taking advantage of the homology between kinase domains of the epidermal growth factor receptors, pan-EGFR inhibitors (TKIs) can be developed to target more than one member of the receptor family simultaneously.

In conclusion, our study demonstrated decreased concentration of HER1 protein and increased HER2, HER3 and HER4 protein concentrations, as well as elevated HER2-HER4 gene expression levels in ovarian cancer patients. Taken together, there may be a shift towards the reliance of cancer cells on HER2/HER3/HER4 signaling during progression from benign to malignant tumors. As we enter the age of molecular targeted therapies and the era of individualized medicine, the design of drugs towards molecular targets in cancer cells need to consider the differential expression of these targets within the cancer. This study provides a rational basis for the use of molecular targets based upon receptor expression and for the design of clinical trials involving targets against the EGFR family members.

\section{Acknowledgements}

The authors would like to thank laboratory technologist Lone Frischknect (Vejle Hospital, Department of Clinical Biochemistry) for her work with RNA purification and HER1-4 gene expression analysis and Sara Egsgaard (Vejle Hospital, Department of Clinical Biochemistry) for performing the protein extractions and the HER1-4 protein quantifications. We also thank our collaborators at Aalborg University Hospital and the Pelvic Mass Group at Rigshospitalet, University of Copenhagen for their kind contribution with patient material. This study was supported by grants from Vejle Hospital, Horsens Hospital, Southern Danish Research Forum of Health Sciences and The Cancer Foundation. The present report was also supported by Siemens Medical Solutions Diagnostics $\mathrm{AB}$ who kindly supported the present study by providing the kits for the HER2 protein quantifications.

\section{References}

1. Yarden Y and Sliwkowski MX: Untangling the ErbB signalling network. Nat Rev Mol Cell Biol 2: 127-137, 2001.

2. Alper O, Bergmann-Leitner ES, Bennett TA, Hacker NF, Stromberg K and Stetler-Stevenson WG: Epidermal growth factor receptor signaling and the invasive phenotype of ovarian carcinoma cells. J Natl Cancer Inst 93: 1375-1384, 2001.

3. Serrano-Olvera A, Duenas-Gonzalez A, Gallardo-Rincon D, Candelaria $\mathrm{M}$ and Garza-Salazar J: Prognostic, predictive and therapeutic implications of HER2 in invasive epithelial ovarian cancer. Cancer Treat Rev 32: 180-190, 2006.

4. Lassus H, Sihto H, Leminen A, Joensuu H, Isola J, Nupponen NN and Butzow R: Gene amplification, mutation, and protein expression of EGFR and mutations of ERBB2 in serous ovarian carcinoma. J Mol Med 84: 671-681, 2006.

5. Stadlmann S, Gueth U, Reiser U, Diener PA, Zeimet AG, Wight E, Mirlacher M, Sauter G, Mihatsch MJ and Singer G: Epithelial growth factor receptor status in primary and recurrent ovarian cancer. Mod Pathol 19: 607-610, 2006.

6. Niikura H, Sasano H, Sato S and Yajima A: Expression of epidermal growth factor-related proteins and epidermal growth factor receptor in common epithelial ovarian tumors. Int J Gynecol Pathol 16: 60-68, 1997.

7. Lassus H, Leminen A, Vayrynen A, Cheng G, Gustafsson JA, Isola $J$ and Butzow R: ERBB2 amplification is superior to protein expression status in predicting patient outcome in serous ovarian carcinoma. Gynecol Oncol 92: 31-39, 2004. 
8. Verri E, Guglielmini P, Puntoni M, Perdelli L, Papadia A, Lorenzi P, Rubagotti A, Ragni N and Boccardo F: HER2/neu oncoprotein overexpression in epithelial ovarian cancer: evaluation of its prevalence and prognostic significance. Clinical study. Oncology 68: 154-161, 2005.

9. Tuefferd M, Couturier J, Penault-Llorca F, Vincent-Salomon A, Broet P, Guastalla JP, Allouache D, Combe M, Weber B, Pujade-Lauraine E and Camilleri-Broet S: HER2 status in ovarian carcinomas: a multicenter GINECO study of 320 patients. PLoS ONE 2: e1138, 2007.

10. Prigent SA, Lemoine NR, Hughes CM, Plowman GD, Selden C and Gullick WJ: Expression of the c-erbB-3 protein in normal human adult and fetal tissues. Oncogene 7: 1273-1278, 1992.

11. Simpson BJ, Weatherill J, Miller EP, Lessells AM, Langdon SP and Miller WR: c-erbB-3 protein expression in ovarian tumours. Br J Cancer 71: 758-762, 1995.

12. Rajkumar T, Stamp GW, Hughes CM and Gullick WJ: c-erbB3 protein expression in ovarian cancer. Clin Mol Pathol 49: M199-M202, 1996.

13. Scoccia B, Lee YM, Niederberger C and Ilekis JV: Expression of the ErbB family of receptors in ovarian cancer. J Soc Gynecol Investig 5: 161-165, 1998 .

14. Tanner B, Hasenclever D, Stern K, Schormann W, Bezler M, Hermes M, Brulport M, Bauer A, Schiffer IB, Gebhard S, Schmidt M, Steiner E, Sehouli J, Edelmann J, Lauter J, Lessig R, Krishnamurthi K, Ullrich A and Hengstler JG: ErbB-3 predicts survival in ovarian cancer. J Clin Oncol 24: 4317-4323, 2006.

15. Gilmour LM, Macleod KG, McCaig A, Gullick WJ, Smyth JF and Langdon SP: Expression of erbB-4/HER-4 growth factor receptor isoforms in ovarian cancer. Cancer Res 61: 2169-2176, 2001.

16. Srinivasan R, Poulsom R, Hurst HC and Gullick WJ: Expression of the c-erbB-4/HER4 protein and mRNA in normal human fetal and adult tissues and in a survey of nine solid tumour types. J Pathol 185: 236-245, 1998.

17. Olsen DA, Ostergaard B, Bokmand S, Wamberg PA, Jakobsen EH and Brandslund I: HER-2 protein concentrations in breast cancer cells increase before immunohistochemical and fluorescence in situ hybridization analysis turn positive. Clin Chem Lab Med 45: 177-182, 2007.

18. Steffensen KD, Waldstrom M, Jeppesen U, Jakobsen E, Brandslund I and Jakobsen A: The prognostic importance of cyclooxygenase 2 and HER2 expression in epithelial ovarian cancer. Int J Gynecol Cancer 17: 798-807, 2007.

19. Press MF, Slamon DJ, Flom KJ, Park J, Zhou JY and Bernstein L: Evaluation of HER-2/neu gene amplification and overexpression: comparison of frequently used assay methods in a molecularly characterized cohort of breast cancer specimens. J Clin Oncol 20: 3095-3105, 2002.

20. Scartozzi M, Bearzi I, Berardi R, Mandolesi A, Fabris G and Cascinu S: Epidermal growth factor receptor (EGFR) status in primary colorectal tumors does not correlate with EGFR expression in related metastatic sites: implications for treatment with EGFR-targeted monoclonal antibodies. J Clin Oncol 22: 4772-4778, 2004

21. Chung KY, Shia J, Kemeny NE, Shah M, Schwartz GK, Tse A, Hamilton A, Pan D, Schrag D, Schwartz L, Klimstra DS, Fridman D, Kelsen DP and Saltz LB: Cetuximab shows activity in colorectal cancer patients with tumors that do not express the epidermal growth factor receptor by immunohistochemistry. J Clin Oncol 23: 1803-1810, 2005.

22. Hebbar M, Wacrenier A, Desauw C, Romano O, Cattan S, Triboulet JP and Pruvot FR: Lack of usefulness of epidermal growth factor receptor expression determination for cetuximab therapy in patients with colorectal cancer. Anticancer Drugs 17: 855-857, 2006.

23. Cunningham D, Humblet Y, Siena S, Khayat D, Bleiberg H, Santoro A, Bets D, Mueser M, Harstrick A, Verslype C, Chau I and van Cutsem E: Cetuximab monotherapy and cetuximab plus irinotecan in irinotecan-refractory metastatic colorectal cancer. N Engl J Med 351: 337-345, 2004.

24. Bookman MA, Malmstrom H, Bolis G, Gordon A, Lissoni A, Krebs JB and Fields SZ: Topotecan for the treatment of advanced epithelial ovarian cancer: an open-label phase II study in patients treated after prior chemotherapy that contained cisplatin or carboplatin and paclitaxel. J Clin Oncol 16: 3345-3352, 1998.
25. Mayr D, Kanitz V, Amann G, Engel J, Burges A, Lohrs U and Diebold J: HER-2/neu gene amplification in ovarian tumours: a comprehensive immunohistochemical and FISH analysis on tissue microarrays. Histopathology 48: 149-156, 2006.

26. Menendez JA, Mehmi I and Lupu R: Trastuzumab in combination with heregulin-activated Her-2 (erbB-2) triggers a receptorenhanced chemosensitivity effect in the absence of Her-2 overexpression. J Clin Oncol 24: 3735-3746, 2006.

27. Tzahar E, Waterman H, Chen X, Levkowitz G, Karunagaran D, Lavi S, Ratzkin BJ and Yarden Y: A hierarchical network of interreceptor interactions determines signal transduction by Neu differentiation factor/neuregulin and epidermal growth factor. Mol Cell Biol 16: 5276-5287, 1996.

28. Witton CJ, Reeves JR, Going JJ, Cooke TG and Bartlett JM: Expression of the HER1-4 family of receptor tyrosine kinases in breast cancer. J Pathol 200: 290-297, 2003.

29. Rubin I and Yarden Y: The basic biology of HER2. Ann Oncol 12 (Suppl. 1): S3-S8, 2001.

30. Skirnisdottir I, Seidal T and Sorbe B: A new prognostic model comprising p53, EGFR, and tumor grade in early stage epithelial ovarian carcinoma and avoiding the problem of inaccurate surgical staging. Int J Gynecol Cancer 14: 259-270, 2004.

31. Ferrandina G, Ranelletti FO, Lauriola L, Fanfani F, Legge F, Mottolese M, Nicotra MR, Natali PG, Zakut VH and Scambia G: Cyclooxygenase-2 (COX-2), epidermal growth factor receptor (EGFR), and Her-2/neu expression in ovarian cancer. Gynecol Oncol 85: 305-310, 2002.

32. Baekelandt M, Kristensen GB, Trope CG, Nesland JM and Holm R: Epidermal growth factor receptor expression has no independent prognostic significance in advanced ovarian cancer. Anticancer Res 19: 4469-4474, 1999.

33. Skirnisdottir I, Sorbe B and Seidal T: The growth factor receptors HER-2/neu and EGFR, their relationship, and their effects on the prognosis in early stage (FIGO I-II) epithelial ovarian carcinoma. Int J Gynecol Cancer 11: 119-129, 2001.

34. Owens OJ and Leake RE: Epidermal growth factor receptor in normal ovaries and benign ovarian tumours. Eur J Obstet Gynecol Reprod Biol 47: 229-233, 1992.

35. Harlozinska A, Bar JK, Sobanska E and Goluda M: Epidermal growth factor receptor and c-erbB-2 oncoproteins in tissue and tumor effusion cells of histopathologically different ovarian neoplasms. Tumour Biol 19: 364-373, 1998.

36. Choong LY, Lim S, Loh MC, Man X, Chen Y, Toy W, Pan M, Chen CS, Poonepalli A, Hande MP, Tan PH, Salto-Tellez M, Wong CY, Shah N, Druker BJ and Lim YP: Progressive loss of epidermal growth factor receptor in a subpopulation of breast cancers: implications in target-directed therapeutics. Mol Cancer Ther 6: 2828-2842, 2007.

37. Dittadi R, Donisi PM, Brazzale A, Cappellozza L, Bruscagnin G and Gion M: Epidermal growth factor receptor in breast cancer. Comparison with non-malignant breast tissue. Br J Cancer 67: 7-9, 1993.

38. Moller P, Mechtersheimer G, Kaufmann M, Moldenhauer G, Momburg F, Mattfeldt T and Otto HF: Expression of epidermal growth factor receptor in benign and malignant primary tumours of the breast. Virchows Arch A Pathol Anat Histopathol 414: 157-164, 1989.

39. Baulida J, Kraus MH, Alimandi M, Di Fiore PP and Carpenter G: All ErbB receptors other than the epidermal growth factor receptor are endocytosis impaired. J Biol Chem 271: 5251-5257, 1996.

40. Bookman MA, Darcy KM, Clarke-Pearson D, Boothby RA and Horowitz IR: Evaluation of monoclonal humanized anti-HER2 antibody, trastuzumab, in patients with recurrent or refractory ovarian or primary peritoneal carcinoma with overexpression of HER2: a phase II trial of the Gynecologic Oncology Group. J Clin Oncol 21: 283-290,2003.

41. Palayekar MJ and Herzog TJ: The emerging role of epidermal growth factor receptor inhibitors in ovarian cancer. Int J Gynecol Cancer (In press). 